\title{
Technological Aspects of the Gamification Model for e-Learning Participant's Engagement
}

\author{
Daina GUDONIENE ${ }^{1}$, Reda BARTKUTE ${ }^{2}$, \\ Danguole RUTKAUSKIENE ${ }^{2}$, Tomas BLAZAUSKAS ${ }^{2}$ \\ ${ }^{1}$ Vilnius University, Institute of Mathematics and Informatics \\ Akademijos St. 4, LT-08663, Vilnius, Lithuania \\ ${ }^{2}$ Kaunas Technology University, Faculty of Informatics \\ Studentu St. 50, LT-51368, Kaunas, Lithuania \\ daina.gudonienedgmail.com, reda.bartkutedktu.lt \\ danguole.rutkauskieneektu.lt, tomas.blazauskasaktu.lt
}

\begin{abstract}
Gamification has been a popular object of researches in various fields. Many researches were made on various aspects of gamification and just very few were oriented to the influence of technological aspects for e-learning participant's engagement. The challenge for our designed model was to find out the new effective ways for the engagement of the students. This paper analysis the prevailing technological aspects and technologies used in e-learning process as well as implementation of various technological solutions in learning platforms. Also, this paper presents a new model of technological aspects of gamification, which was implemented at the Faculty of Informatics to engage students to get better results in learning programming.
\end{abstract}

Keywords: gamification models, technological aspects, motivational tools, engagement, gamification

\section{Introduction}

Different models of gamification became a focus of interest in various fields (Kuo and Chuang, 2016). The interest in gamification was boosted by quick positive changes in learner's attitude to learning process (Luo et al., 2015). Despite of the interest in gamification which has started few years ago (Pedreira et al., 2015); gamification is not a new learning method in the field of education (Kuo and Chuang, 2016). However, just few years ago it was implemented in e-learning.

The complexity of technologies opened new opportunities to implement different gamification models in e-learning (Iosup and Epema, 2014). Emerging technologies used in gamification stimulated the creation of new, more complex gamification models (Prakash and Rao, 2015) based on the learner's cognitive, emotional and social capabilities (Huber and Milty, 2014). This obligates to use a wide spectrum of different technologies to satisfy the each learner's need.

Different scenarios, choices and roles stimulate to create engaging game environments by using various types of technologies (Thiebes et al., 2014). Since the same learning 
model can be implemented in many different ways (Ferron et al., 2014), the same technologies used in different contexts create the impression of novelty and increase the interest in specific learning object (Attali and Arieli-Attali, 2015). For this reason, the same game mechanics can be used in different contexts.

Most of gamification models are based on the rewarding system: 'win the game and get the prize' (Caton and Greenhill 2014). Following that, the tools used in platforms are based on pointing system where a reward depends on learner's performance or completed tasks. Various badges, leader boards, tokens and gamified currency are used for implementation as tools for rewarding learning method to the learning platform.

\section{Overview of technological aspects of the Gamification Model}

Gamification models have adopted various technological solutions to increase Learner's Engagement. Many of them use pretty simple technologies such as implemented plug-ins based on rewarding techniques (Kim and Lee, 2013). Those gamification techniques strive to leverage people's natural desires for socializing, learning, competition or achievement. However, there is much more complicated technological solutions such as video games or games based on social interaction (Alves et al., 2014) and their implementation in learning platforms. Most of technological aspects contain three main elements which are the key factors for successful gamification model (Engler, 2012). These factors are game mechanic types (progression, feedback, behavioural), types of gamer personalities (achievers, explorers, socializers, killers) and boosts (engagement, loyalty, time spent, influence, fun, SEO, user generated, content) (see Table 1).

Table 1. The categories of games mechanics, gamer personalities and boosts

\begin{tabular}{|c|c|c|}
\hline Game Mechanic Types & Types of gamer personalities & Boosts \\
\hline $\begin{array}{l}\text { Progression: supports } \\
\text { development of skills; }\end{array}$ & $\begin{array}{l}\text { Achievers: like to gain "points", } \\
\text { levels, equipment and other } \\
\text { measurements reflecting success; }\end{array}$ & $\begin{array}{l}\text { Engagement; } \\
\text { Loyalty; } \\
\text { Time Spent; }\end{array}$ \\
\hline $\begin{array}{l}\text { Feedback: positive and } \\
\text { negative feedback; }\end{array}$ & $\begin{array}{l}\text { Explorers: like discovering } \\
\text { areas, creating maps and learning } \\
\text { about hidden places; }\end{array}$ & $\begin{array}{l}\text { Influence; } \\
\text { Fun; } \\
\text { SEO; }\end{array}$ \\
\hline $\begin{array}{l}\text { Behavioural: deals with } \\
\text { human behaviour and } \\
\text { psyche. }\end{array}$ & $\begin{array}{l}\text { Socializers: they choose the } \\
\text { game because of the social } \\
\text { effects, not because of the game } \\
\text { itself; } \\
\text { Killers: like competing with } \\
\text { other players. }\end{array}$ & $\begin{array}{l}\text { User; } \\
\text { Generated; } \\
\text { Content; } \\
\text { Virality. }\end{array}$ \\
\hline
\end{tabular}

Iosup and Epema (2014) indicated 7 core tools for implementation of gamification. Three tools are related with games mechanics: 1) pointing system; 2) Levels, access and power; 3) leader-boards. These tools make games more competitive and stimulate learner's motivation to lead the game as well as get engaged into the game and complete levels. Other four core tools are related with dynamics of the game: 1) status displays (badges and etc.); 2) on-boarding systems; 3) social engagement tools; 4) unlocking 
content. These core tools keep up the learner's motivation and stimulate their interest in further learning process. Some of tools (badges, leader boards) can be found implemented on learning platforms (e.g. Moodle). Others, such as interaction tools and levels, might need additional methods of implementation on the platform (Contador and Marczewski, 2015) as it depends on the gamified context whether the whole game or separate parts of the game are embedded into the platform

\section{A methodology for implementation of technologies in Gamification Model}

Different types of gamification models can be implemented using different kinds of tools. Apostol et al. (2013) identified eight core elements for effective gamified context. Thus, gamified context must have: 1) clear rules; 2) clear goals and outcomes;

Table 2. Games mechanics used in gamification (Dicheva et al., 2015)

\begin{tabular}{|c|c|}
\hline Design principles & Game mechanics \\
\hline \multicolumn{2}{|l|}{$\begin{array}{l}\text { Goals: specific, clear, moderately difficult, immediate } \\
\text { goals. }\end{array}$} \\
\hline \multicolumn{2}{|l|}{$\begin{array}{l}\text { Challenges and quests: clear, concrete, actionable } \\
\text { learning tasks with increased complexity. }\end{array}$} \\
\hline $\begin{array}{l}\text { Customization: personalized experiences, adaptive } \\
\text { difficulty; challenges that are perfectly tailored to the } \\
\text { player's skill level, increasing the difficulty as the } \\
\text { player's skill expands. }\end{array}$ & Multiple game pathways \\
\hline Progress: visible progression to mastery & $\begin{array}{l}\text { Points, progress bars, } \\
\text { levels, virtual } \\
\text { goods/currency }\end{array}$ \\
\hline \multicolumn{2}{|l|}{$\begin{array}{l}\text { Feedback: immediate feedback or shorten feedback } \\
\text { cycles; immediate rewards instead of vague long-term } \\
\text { benefits. }\end{array}$} \\
\hline Competition and cooperation/social engagement loops & $\begin{array}{l}\text { Badges, leader-boards, } \\
\text { levels, avatars }\end{array}$ \\
\hline Accrual grading & Points \\
\hline $\begin{array}{l}\text { Visible status: reputation, social credibility and } \\
\text { recognition. }\end{array}$ & $\begin{array}{l}\text { Points, badges, leader- } \\
\text { boards, avatars }\end{array}$ \\
\hline \multicolumn{2}{|l|}{ Access/unlocking content } \\
\hline $\begin{array}{l}\text { Freedom of choice: multiple routes to success, allowing } \\
\text { students to choose their own sub-goals within the larger } \\
\text { task }\end{array}$ & Multiple game pathways \\
\hline \multicolumn{2}{|l|}{$\begin{array}{l}\text { Freedom to fail: low risk from submission, multiple } \\
\text { attempts. }\end{array}$} \\
\hline Storytelling & Avatars \\
\hline New identities and/or roles & Avatars \\
\hline \multicolumn{2}{|l|}{ On-boarding } \\
\hline Time restriction & Countdown clock \\
\hline
\end{tabular}


3) feedbacks and rewards; 4) tasks for problem solving; 5) story; 6) player(s); 7) safe environment; 8) sense of mastery. These elements can be seen mostly through separate gamified elements. Dicheva et al. (2015) following the core gamification elements made a research on literature for design principles and technologies used to deliver them into the gamified context. The results of the research are delivered on Table 2.

Different gamification models require different technologies to be implemented (Hanus and Fox, 2015). The game mechanics used in gamification depends on the creator who decides what level of gamification will be used in the learning process (Seaborn and Fels, 2015). Thus, the same model might use different technologies and reach different results as well as satisfy the needs of different kind of learners.

\section{A model of technological aspects of the Gamification Model}

The Gamification model is based on games mechanics such as rewarding system, customization and leader-boards.

Rewarding system (e.g. pointing system and rewards) is one of common and most popular games mechanics implemented in gamified learning content (Hanus and Fox, 2015). It is not complicated to implement since many of learning platforms already have it or there are wide range of plug-ins to install (Huber and Hilty, 2014). In created model, pointing system is responsible for the algorithm for counting the student's performance. The exact amount of points gained for the completed task depends on the maximum possible points to gain for the task. Points are used as the main index to get into new level or get rewards.

For the deeper engagement the system of levels in the game was created. The levels have been implemented with a specific enter criteria which is based on the specific amount of collected points. Each level means the specific level of mastery.

Customization in the model is implemented by the free choice of learning content and tasks. The learner decides what he/she wants to learn and what tasks want to take for gaining points. This lets the learner create his/her own learning paths based on her/his needs and interest.

For social status, the leader-boards were also implemented in the model. The implemented leader-boards are based on the sum of points and display the leaders from all levels. The place in the leader-board depends on the amount of collected points and badges which can be gained for completing certain tasks with the certain amount of points.

\section{The case of experiment}

The gamification method, based on activity points, was implemented on the platform. The gamified platform was tested by totally 48 first year students of Informatics faculty and control group of 95 first year students.

The tutorials (learning content) and tasks (practical exercises and exams) are delivered in the platform. Each of tutorial or task is evaluated by the specific amount of point which learner gets for completion. Tutorials are not mandatory if user want to participate in the contest. Exams are required to be done for students to get a certificate issued by university. It is important to note, that learners can choose their own path of learning 
which means that learning process is not restricted and learners can choose what tasks they want to complete. But it is essential to remember that more tasks you complete, more points you get.

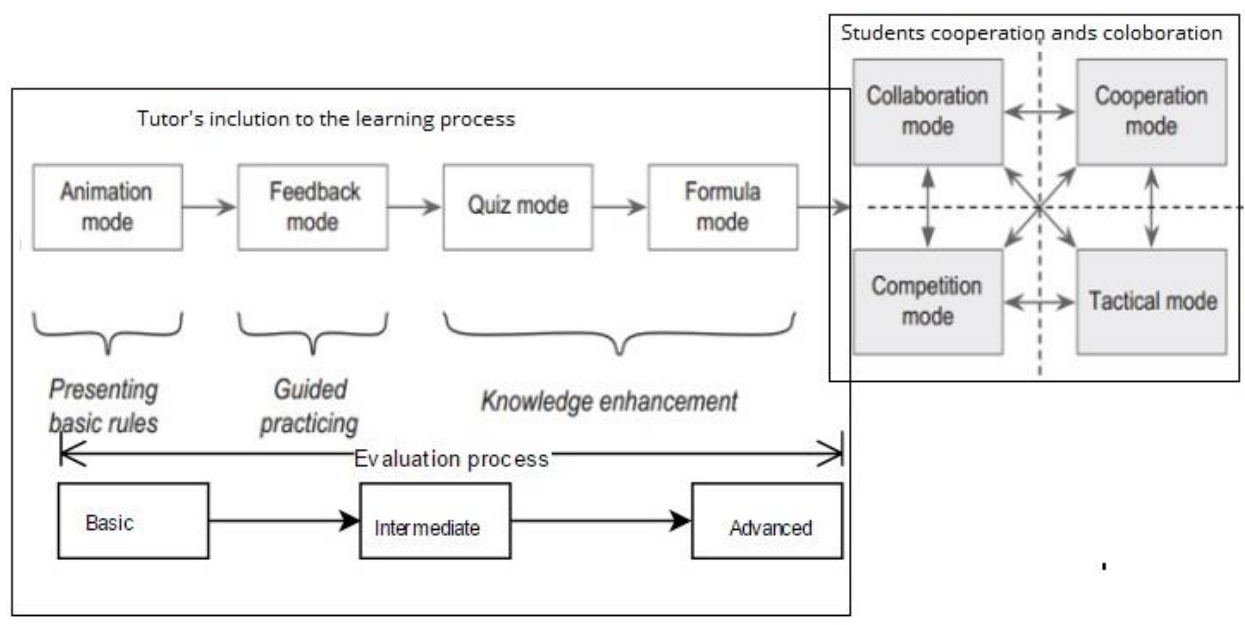

Fig. 1. Informic gamification model based on levels.

Finishing exams and tutorials gives points for the users (0-50 for tutorial and 0-100 for exam) which are displayed in top 100-leader board and ratings view and show user points and badges (badges such as "Nežiniukas" are gained for reaching 1000 points milestone) for everyone (see Fig. 1).

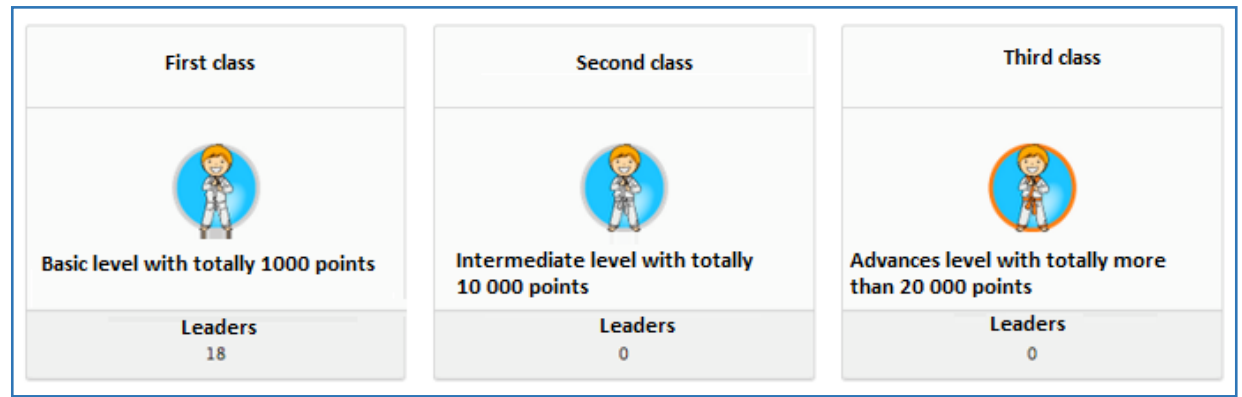

Fig. 2. The example of levels

Multiple types of badges where awarded for the students as ladders to next group (see Fig. 2). The primary level of learner is indicated by level-assessment test. There are three levels of model: basic level for newbies in programming, intermediate for already having some skills in programming and advances for people who demonstrate higher than average skills in programming. Each level indicates a specific level of mastery in programming which can be reached by two ways: collecting points and completing level assessment test. 
Students are divided in two groups: control group and the group, which has opportunity to solve additional problems. Control group consists of 95 students. Group, which has opportunity to solve additional problems consists of 48 students. Learning results of two groups are compared (Fig. 3).

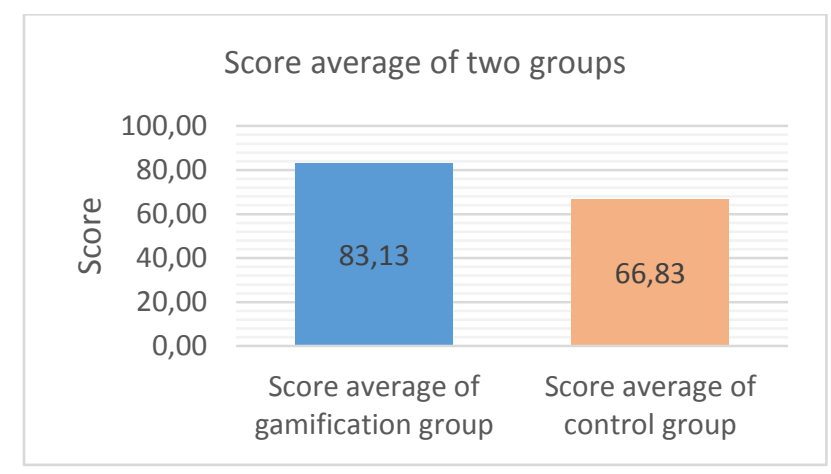

Fig. 3. The average score of gamification group and control group.

The average score of gamification group was 83,13 . The average score of control group was 66,83 (see Fig. 3). The gamification group has shown 19,61\% higher score average.

\section{Conclusions}

Every gamification model contains of three key factors: game mechanics type, types of gamer personality and boosts. All these factors together create a full package of gamification technologies directed to learner's engagement and stimulate to learner's motivation to compete and win.

The developed model engages students to learn more effectively and even to be interested in deeper knowledge that shows the evaluation results of piloting group (Fig. 3).

The gamification model's technological aspects are based on three main game mechanics: rewarding system (points and badges), customization (customized path through the learning content) and leader boards. All of these elements were implemented to the e-platform for programming learning. However, it is created a unique gamified learning environment where traditional e-learning is supplemented by gamified tools for student's engagement.

\section{Acknowledgements}

The paper presents the results of the project "Educational content modernization using new methods and tools for competences development of educators" (EEE-LT08-ŠMM01-K-02-033). 


\section{References}

Apostal, S., Zaharescu, L, Alexe, I. (2013), Gamification of Learning and Educational Games, The $9^{\text {th }}$ International Scientific Conference eLearning and Software for Education.

Alves, F. P., Maciel, C., Anacleto, J. C. (2014), Guidelines for the Gamification in Mobile Social Networks, Social Computing and Social Media, Vol. 8531, pp. 559-570.

Attali, Y., Arieli-Attali, M. (2015), Gamification in assessment: Do points affect test performance?, Computers \& Education, Vol. 83, pp. 57-63. Retrieved from: http://www.sciencedirect.com/science/article/pii/S0360131514002899

Caton, H., Greenhill, D. (2014), Rewards and Penalties: A Gamification Approach for Increasing Attendance and Engagement in an Undergraduate Computing Module, International Journal of Game-Based Learning, Vol. 4, Iss. 3, pp. 12.

Cantador, I., Marczewski, A. (2015), Validating Gamification Mechanics and Player Types in an E-learning Environment, Design for Teaching and Learning in a Networked World (Lecture Notes in Computer Science), Vol. 9307, pp. 568-572.

Chen, P. D., Guidry, K. R., Lambert, A. D. (2009), Engaging Online Learners: A Quantitative Study of Postsecondary Student Engagement in the Online Learning Environment, Annual Meeting of the American Education Research Association, San Diego, JAV, April 13-17. Retrieved from: http://cpr.indiana.edu/uploads/engaging $\% 20$ online $\% 20$ learners.pdf

Dicheva, D., Dichev, C., Agre, G., Angelova, G. (2015), Gamification in Education: A systematic Mapping Study, Educational Technology and Society, Vol.18, No. 3, pp. 75-88.

Engler, R. (2012), Serious Games - Gamification of Education, Retrieved from: http://www.cs.vu.nl/ eliens/sg/local/essay/12/08.pdf

Ferron, M., De Paoli, S., Massa, P. (2014), Uniquitous games and gamification for well-being, EAI Endorsed Transactions on Ambient System, Vol. 14, No. 3.

Iosup, A., Epema, D. (2014), An experience report on using gamification in technical higher

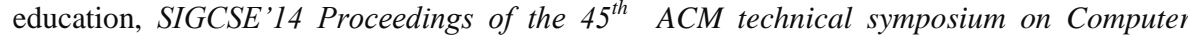
science education, ACM New York, NY, USA, pp. 27-32, ISBN: 978-1-4503-2603-6.

Hamari, J., Koivisto, J., Sarsa, H. (2014), Does gamification work? A literature review of empirical studies on gamification, System sciences (HICSS) $47^{\text {th }}$ Hawaii International Conference, HICSS, Hawaii (2014), pp. 3025-3034. Retrieved from: http://www.sciencedirect.com/science/article/pii/s0360131514002000

Hanus, M. D., Fox, J. (2015), Assessing the effects of gamification in the classroom: A longitudinal study on intrinsic motivation, social comparison, satisfaction, effort, and academic performance, Computers \& Education, Vol. 80, pp. 152-161.

Huber, M. Z., Hilty, L. M. (2014), Gamification and Sustainable Consumption: Overcoming the Limitations of Persuasive Technologies, Advances in Intelligent Systems and Computing, Springer, ISSN: 2194-5357.

Kim, J. T., Lee, W. H. (2013), Dynamical model for gamification of learning (DMGL), Multimedia Tools and Applications, Vol. 74, Iss. 19, pp. 8483-8493.

Kuo, M. S., Chuang T. Y. (2016), How gamification motivates visits and engagement for online academic dissemination - An empirical study", Computers in Human Behavior, Vol. 55, Part A, pp. 16-27.

Luo, S., Yang, H., Meinel, C. (2015), Reward-based Intermittent Reinforcement in Gamification for E-learning, Proceeding of the $7^{\text {th }}$ International Conference on Computer Supported Education (CSEDU-2015), pp. 177-184, ISBN: 978-989-758-107-6.

Pedreira, O., Garcia, F., Brisaboa, N., Piattini, M. (2015), Gamification in software engineering A systematic mapping, Information and Software Technology, Vol. 57, pp. 157-168. Retrieved from:

http://www.sciencedirect.com/science/article/pii/s0950584914001980 
Prakash, E. C., Rao, M. (2015), Transforming Learning and IT Management through Gamification, International Series on Computer Entertainment and Media Technology, Springer, ISBN: 978-3-319-18699-3.

Seaborn, K., Fels, D. (2015), Gamification in Theory and Action: A Survey, International Journal of Human-Computer Studies, Vol. 74, pp. 14-31.

Thiebes, S., Lins, S., Basten, D. (2014), Gamifying Information Systems - A Synthesis of Gamification Mechanics and Dynamics, Proceedings of the European Conference on Information Systems (ECIS) 2014, Tel Aviv, Israel, June 9-11, ISBN: 978-0-9915567-0-0.

Received May 3, 2016, revised August 29, 2016, accepted September 19, 2016 